Article

\title{
Dynamic Simulation of Integrated Cleaner Production Strategies towards High Quality Development in a Heavily Air-Polluted City in China
}

\author{
Jing Shao ${ }^{1}$, Nan Xiang ${ }^{1, *} \mathbb{C}$, Yutong Zhang ${ }^{1}, \mathrm{Xiang} \mathrm{Li}^{2}$ and Guihua Liang ${ }^{2}$ \\ 1 College of Economics and Management, Beijing University of Technology, Beijing100124, China; \\ starlight@emails.bjut.edu.cn (J.S.); zhangyt13820086692@emails.bjut.edu.cn (Y.Z.) \\ 2 School of Economics and Management, Beijing University of Chemical Technology, Beijing 100029, China; \\ 2020200836@mail.buct.edu.cn (X.L.); liangguihua@buct.edu.cn (G.L.) \\ * Correspondence: xiangnan@bjut.edu.cn
}

Citation: Shao, J.; Xiang, N.; Zhang, Y.; Li, X.; Liang, G. Dynamic

Simulation of Integrated Cleaner Production Strategies towards High Quality Development in a Heavily Air-Polluted City in China. Sustainability 2021, 13, 8951. https:// doi.org/10.3390/su13168951

Academic Editor: Vladimir Strezov

Received: 1 July 2021

Accepted: 5 August 2021

Published: 10 August 2021

Publisher's Note: MDPI stays neutral with regard to jurisdictional claims in published maps and institutional affiliations.

Copyright: ( $\odot 2021$ by the authors Licensee MDPI, Basel, Switzerland. This article is an open access article distributed under the terms and conditions of the Creative Commons Attribution (CC BY) license (https:// creativecommons.org/licenses/by/ $4.0 /)$.

\begin{abstract}
Air-polluted cities, mostly dominated by heavy industries, are facing the dilemma of economic growth and environment deterioration. Tangshan is the largest iron and steel manufacturing city in China, and its air quality rankings belong to the worst 10 among 168 monitored cities of China in a decade. It is extremely important to adopt cleaner production strategies to facilitate high quality development. This study originally created an integrated plan (DOMCLP) to propose feasible pathways to underpin policy making by local authorities and managers from multiple perspectives. These include "Top-Down" measures-financial subsides and environmental efficiency improvement from a macro vision and industrial restructuring from a mezzo vision—and a "Bottom-Up" strategy of optimal technology selection from a micro vision. The DOMCLP simulated the environmental and economic impacts of different cleaner production strategy mixes from 2020 to 2030. Under the cleaner production scenario, which integrates all three measures, the targeted annual economic growth rate can reach $6.56 \%$ over the study period without deterioration of the air environment, and air pollutant emissions can be reduced by more than $74 \%$. Meanwhile, the production of the iron and steel industry can achieve a $43 \%$ capacity growth, in which the intensity of $\mathrm{SO}_{2}$ and $\mathrm{NO}_{x}$ can be reduced by 97 and $87 \%$, respectively. Furthermore, upgrading the optimal air pollutant control technology is proven to be more effective than other incentive measures and calls for systematic optimization and technology choice shift from end treatment to source and process treatment in the long run. This study proves that the integrated cleaner production strategies can realize a strong decoupling effect on the scale of -5.89 to -0.58 to accomplish balanced economic development and environmental improvement in heavily air-polluted cities, which is significant as other industrial cities begin to move toward a high quality development.
\end{abstract}

Keywords: decoupling analysis; environmental efficiency; industrial structure adjustment; InputOutput model; system dynamics; optimal technology selection

\section{Introduction}

With accelerating urbanization in China, heavy industry is developing rapidly to support infrastructure construction and economy growth. However, because of its high energy consumption and heavy pollution features [1], industrial production accounted for approximately $65.9 \%$ of China's total energy consumption and emitted large quantities of $\mathrm{SO}_{2}, \mathrm{NO}_{x}$, and other pollutants, accounting for $86.5 \%\left(\mathrm{SO}_{2}\right)$ and $44.5 \%\left(\mathrm{NO}_{\mathrm{x}}\right)$ of the national total emissions in 2019. Air pollution problems are occurring mainly in industrial cities of China.

Industrial cities face the dilemma of economic slowdown and environmental pressure in China. The iron and steel manufacturing industry is one of the major industries, consuming $27.9 \%$ of the industry energy demand and generating 29.2 and $27.4 \%$ of $\mathrm{SO}_{2}$ 
and $\mathrm{NO}_{x}$, respectively [2]. Therefore, the steel industry has a serious negative impact on the environment [3].

According to the World Steel Association, 996.3 million tons of crude steel were produced in China in 2019, accounting for 53.3\% of the world's total production. Tangshan City is the largest iron and steel manufacturing-intensive city; its production of crude steel in 2019 was 136.9 million tons, accounting for $13.7 \%$ of the national steel production. Moreover, the output of crude steel in Tangshan City is 37.6 million tons, 491 million tons more than that of Japan and the United States [4,5]. As a result of the large production, Tangshan City's air quality rankings belong to the worst 10 among 168 monitored cities of China in a decade. The average annual concentrations of $\mathrm{SO}_{2}$ and $\mathrm{NO}_{\mathrm{x}}$ reached 18 and $46 \mu \mathrm{g} / \mathrm{m}^{3}$, respectively, in 2020 [6]. Moreover, the intensity of air pollutants emitted by Tangshan City's steel industry is much higher than that of other developed steel producers [7]. Under significant environment pollution pressure, its economic growth has slowed down since 2010. In 2017, the economic growth rate was only $2.7 \%$, which was much lower than the national average of $6.5 \%$. In the same year, Tangshan City was designated as an industrial transformation demonstration zone in China, which is a national strategy involving the transformation and development of industrial cities [8].

To solve the problems of slow economic development and serious environmental pollution in China's heavily air-polluted industrial cities, it is necessary to implement cleaner production to accomplish high quality transformation and development. Cleaner production can not only effectively improve the utilization rate of resources but also reduce energy consumption and pollutant discharge [9]. The United Nations Environment Programme defined cleaner production as a key method in achieving green development because it continuously applies comprehensive environmental strategies to processes, products, and services to improve efficiency and reduce risks to humans and the environment [10]. Technological innovation's impacts on cleaner production should also be emphasized in the reduction of environmental pollution and energy consumption [11].

Regarding research perspectives on the high quality development of industrial cities, previous studies have analyzed separate macro, mezzo, and micro visions to address the severe environmental and economic problems existing in industrial cities. A macro vision mainly considers the environmental policies of national and local governments [12-14], energy consumption [15-17], economic development [18,19], tax policy [20,21], and trade policy $[22,23]$. A mezzo vision includes industrial optimization and adjustment and cleaner industrial production capacity $[24,25]$, which mainly combines the macro and mezzo dimensions but does not consider technology from a micro perspective. Most previous studies on the micro vision focus on the impacts on the environment or economy of specific steelmaking processes [26] or energy saving and emission reduction technologies [27,28]. In addition, this research perspective mostly considers heavy industry rather than industrial cities. Xu et al. [29] proposed an optimal path for steel cities to achieve green economic transformations through industrial restructuring and environmental treatment efficiency improvements, but they did not analyze specific technical selection schemes. Regional environmental and economic improvement cannot be achieved by considering only one angle, it must involve a combination of macro, mezzo, and micro approaches.

Regarding the research time scale, current research is abundant in historical pattern discovery but limited in scientific predictions and policies regarding the future development of industrial cities. Several studies have expounded or compared the economic and environmental situations of industrial cities [30,31] and thus proposed suggestions for promoting their green development from the perspective of government governance and planning. In previous atmospheric-related studies, the decoupling theory, a useful tool to evaluate the trade-offs between the environment and economy, was mainly used to analyze historical data rather than predicted results [32-34], which limited its policy guidance.

In general, previous scholars have adopted various research methods in exploring pathways for industrial cities, such as regression analysis [35], the CGE model [36], InputOutput method [37,38], and life cycle assessment [39,40]. In their previous study, Xu 
et al. [29] divided the current methods into two categories: summaries of historical patterns or current situations and future development forecasting and planning. Overall, this study found that current methods lack future orientation and innovation, and the authors provided a new method combining system dynamics with the Input-Output method and technical factors of the Energy-Economy-Environment (3E) system to provide feasible suggestions for the green transformation of steel cities. However, this study did not provide specific technical solutions and optimal technology selection schemes. As technology plays an essential role in the technological progress and sustainable development of industrial cities [41-43], herein we concretize the technical factors into clean production technical solutions in order to further examine the influence of technology. Several technological studies have considered technology as an influencing factor in their calculation models $[44,45]$ or evaluated their performance $[29,46,47]$ and cost-effectiveness $[27,28,48]$ in air pollution treatment, thereby compiling, essentially, a summary of historical and current situations. From the perspective of simulation and prediction, the current studies do not provide adequate guidance for policy formulation.

Based on the limitations of the above studies, this study aims to examine the significance and propose a strategy of integrated cleaner production for environmental improvement and economic development in air-polluted cities. First, we define cleaner production by combining "Top-Down" and "Bottom-Up" schemes in three capacities: environmental efficiency improvement from a macro perspective, industrial structure adjustment from a mezzo perspective, and cleaner production technology introduction from a micro perspective. The dynamic optimization modeling and simulation approach is adopted to comprehensively and systematically evaluate the influence of incentive strategies on the regional atmospheric environment and economic development.

Using Tangshan City as an example, this study comprehensively identifies the optimal roadmap of cleaner production in industrial cities from multiple perspectives and scales. Second, this study combines the Input-Output model, the system dynamics method, and multi-objective optimization to develop a comprehensive dynamic optimization model of cleaner production (DOMCLP) in a typical industrial city. This DOMCLP can be easily extended or adapted to other regions with air pollution. Moreover, dynamic simulations are used to predict the economic and environmental development from 2020 to 2030 in a case study; then, forecast data are used to analyze the decoupling effect of economic and environmental factors from a long-term perspective. This study aims to provide a scientific method and effective strategies for the high quality development of heavily air-polluted cities.

\section{Methodology}

\subsection{Modeling Framework}

This study applied a dynamic optimization model that comprises economic and environmental systems. The model we constructed is a novel model with integration of the optimal technology selection model and the Environment-Economy-Energy model, and essentially a multi-objective linear programming problem based on the Input-Output model and system dynamics.

As shown in Figure 1, the DOMCLP model calculates the economic and atmospheric environmental development with three incentive cleaner production strategies (POL1, POL2, and POL3). A to F are six advanced cleaner production technologies, their relevant parameters appear in the Appendix. The environmental incentive policies stimulus control effects were systematically evaluated by analyzing the balance of value and material flows. The Input-Output model provides a basic economic model for the DOMCLP, while environmental pollutant emissions and energy demands are connected to industrial production and residential life. 


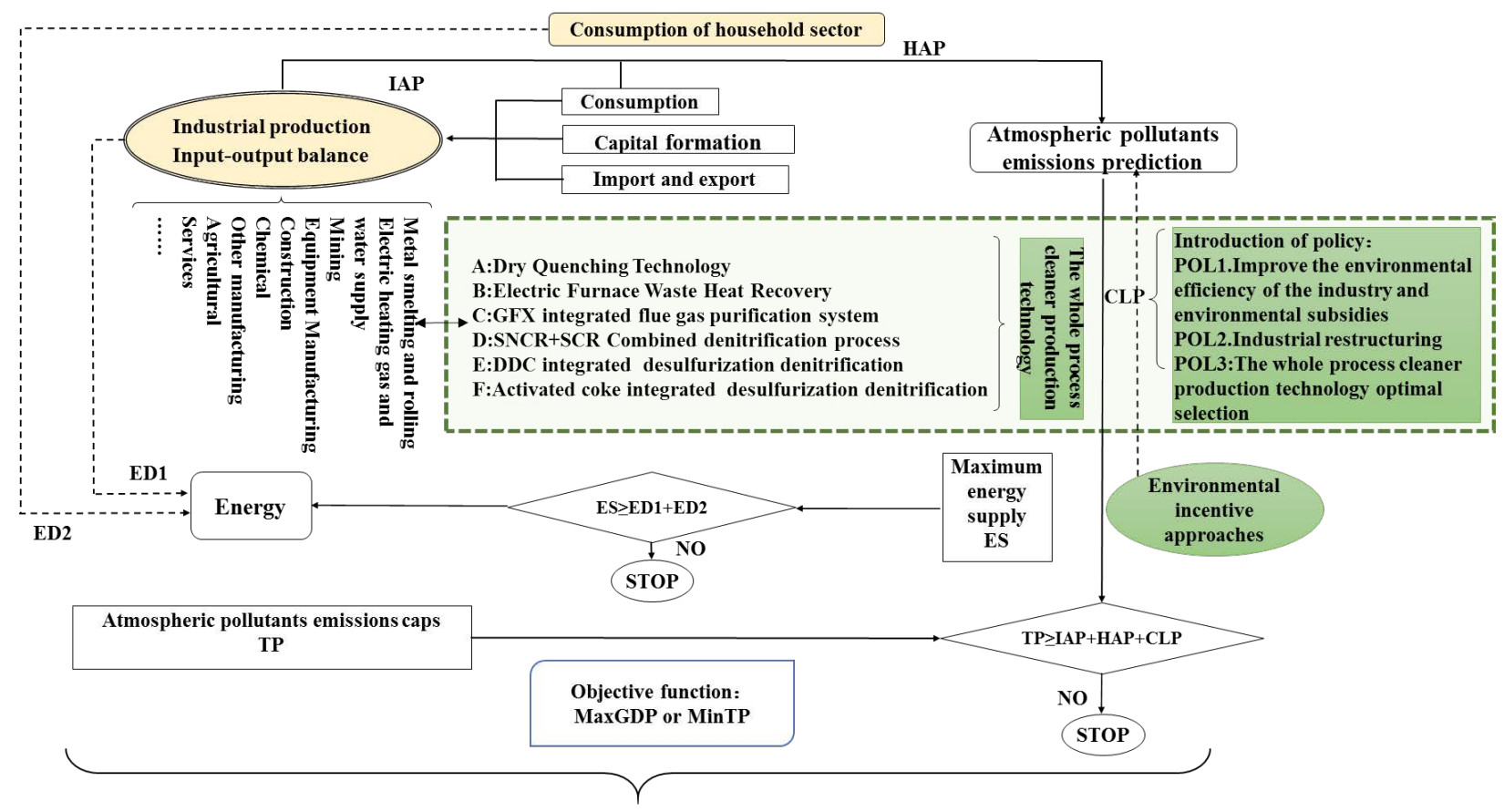

The balanced development of economic growth and environmental protection

Figure 1. DOMCLP model framework. HAP: Household Air Pollution, IAP: Industrial Air Pollution, CLP: Cleaner Production, ED: Energy Demand, ES: Energy Supply, TP: Total Pollution, GDP: Gross Domestic Product, PLO1: Cleaner Production Strategy 1, POL2: Cleaner Production Strategy 2, PLO3: Cleaner Production Strategy 3.

\subsection{Economic and Social Model}

Using the Input-Output method as the DOMCLP model basis, a 2016 Tangshan InputOutput table (Supplementary Sheet 1) was compiled based on the input coefficients of the Hebei Province in 2012 and the data of each industry in Tangshan City in 2016 [49], assuming the direct input coefficients remained unchanged. There are two kinds of variables in the model: endogenous (en), which is determined by the model operation, and exogenous (ex), which is derived from actual data. The simulation period was 15 years, from 2016 to 2030, and based on the initial data in 2016.

\section{Objective function:}

The objective of the DOMCLP model is to maximize the economy under a constraint of the atmospheric environment; it is defined as maximizing the GDP, which is determined by the production and value-added ratios of each industry as follows:

$$
\begin{gathered}
M A X \sum_{t} \frac{1}{(1+\rho)^{t-1}} \operatorname{GDP}(t), \\
\operatorname{GDP}(t)=\sum_{i=1}^{11} I V A_{i} \times Y_{i}(t)
\end{gathered}
$$

where $t$ is the simulation period, with values from 1 (2016) to 15 (2030); GDP(t) is the gross regional production of Tangshan City in year $t(\mathrm{en}), \rho$ is the social discount rate $\left(0.05 ;\right.$ ex), $Y_{i}(t)$ is the output of the industry $i$ in Tangshan City in year $t(\mathrm{en}), I V A_{i}$ is the value-added rate of the industry $i$ (ex), and $i$ represents the 11 major industries in Tangshan City $(i=1$ : agriculture, forestry, husbandry, fishery, and their service industries; $i=2$ : metal smelting and rolling industry; $i=3$ : mining; $i=4$ : equipment manufacturing; $i=5$ : chemical industry; $i=6$ : non-metallic mineral products; $i=7$ : production and supply of electricity, heat, gas, and water; $i=8$ : other manufacturing; $i=9$ : construction; $i=10$ : transportation, warehousing, and postal services; and $i=11$ : services). 


\subsection{Cleaner Production Incentive Approaches}

Industrial restructuring. Industrial restructuring is the first incentive method to improve the trade-offs between economic development and environmental protection. According to the Input-Output theory and the law of economic operation, production and consumption in a social economy must meet an Input-Output balance of:

$$
\begin{gathered}
{\left[\begin{array}{c}
Y_{1}(t) \\
Y_{2}(t) \\
\vdots \\
Y_{10}(t) \\
Y_{11}(t)
\end{array}\right] \geq\left[\begin{array}{ccc}
a 1,1 & \cdots & a 1,11 \\
\vdots & \ddots & \vdots \\
a 11,1 & \cdots & a 11,11
\end{array}\right] \cdot\left[\begin{array}{c}
Y_{1}(t) \\
Y_{2}(t) \\
\vdots \\
Y_{10}(t) \\
Y_{11}(t)
\end{array}\right]+\left[\begin{array}{c}
T C_{1}(t) \\
T C_{2}(t) \\
\vdots \\
T C_{10}(t) \\
T C_{11}(t)
\end{array}\right]+\left[\begin{array}{c}
N E X_{1}(t) \\
N E X_{2}(t) \\
\vdots \\
N E X_{10}(t) \\
N E X_{11}(t)
\end{array}\right]+\left[\begin{array}{c}
I N V_{1}(t) \\
I N V_{2}(t) \\
\vdots \\
I N V_{10}(t) \\
I N V_{11}(t)
\end{array}\right]} \\
\text { where }\left[\begin{array}{c}
Y_{1}(t) \\
Y_{2}(t) \\
\vdots \\
Y_{10}(t) \\
Y_{11}(t)
\end{array}\right] \text { is the output value of the } 11 \text { industries in year } t \text { (en), and } \\
\left.\left[\begin{array}{ccc}
a 1,1 & \cdots & a 1,11 \\
\vdots & \vdots \\
a 11,1 & \cdots & a 11,11
\end{array}\right] \text { is the input coefficient matrix (ex), }\left[\begin{array}{c}
T C_{1}(t) \\
T C_{2}(t) \\
\vdots \\
T C_{10}(t) \\
T C_{11}(t)
\end{array}\right] \begin{array}{c}
I N V_{1}(t) \\
I N V_{2}(t) \\
\vdots \\
I N V_{10}(t) \\
I N V_{11}(t)
\end{array}\right]
\end{gathered}
$$

the total investment in year $t$ (en).

Environmental efficiency improvement. Air pollutants are mainly caused by industrial production and residential living. Air pollutant emission is determined by each sector's production value and its distinct emission intensity of pollutants. Industrial pollutant emission initial data (Supplementary Sheet 2) mainly come from research statistics and the Tangshan Statistical Yearbook [49]. The improvement of environmental efficiency is the reduction of pollutants emitted by a unit of production in each industry. In this study, the environmental efficiency improvement rate was set to 10\% [50]. As pollutant emissions are associated with the residential living population, they are calculated by each unit of population. The average population growth rate was determined based on the number of permanent residents in 2016 and the natural population growth rate of Tangshan City over the past 10 years.

$$
\begin{gathered}
T P^{P}(t)=I A P^{p}(t)+H A P^{p}(t)-C L P^{P}(t), \\
I A P^{p}(t)=\sum_{i=1}^{11} \beta \cdot e p_{i}^{p} \cdot Y_{i}(t) \\
H A P^{p}(t)=e p_{h}^{p} \cdot Z(t)
\end{gathered}
$$

where $T P^{P}(t)$ is the total air pollutant emissions in Tangshan City in year $t$ (en). Note that when $p=1$, it refers to $\mathrm{SO}_{2}$ emissions, and when $p=2$, it refers to the $\mathrm{NO}_{\mathbf{x}}$ emissions. $I A P^{p}(t)$ denotes the emissions caused by industrial production in year $t(\mathrm{en}), \operatorname{HAP}^{p}(t)$ represents the emissions caused by residential living in year $t(\mathrm{en}), C L P^{P}(t)$ denotes the air pollutants reduced by the whole-process control technology in year $t(\mathrm{en}), e p_{i}^{p}$ represents the emission intensity of air pollutants in the industry $i$ (ex) (Supplementary Sheet 3), and $\beta$ represents the industry environmental efficiency, which is 1 before improvement and 
0.9 after improvement (ex). Further, $Z(t)$ is the permanent resident population of Tangshan City in year $t(\mathrm{en})$, and $e p_{h}^{p}$ denotes the residential living atmospheric pollutant emission intensity (ex).

Optimal technology selection. Currently, the most used desulfurization and denitrification processes are the limestone-gypsum method and selective non-catalytic reduction (SNCR) denitrification technology [51,52], which account for more than $95 \%$ of the pollutant removal technologies employed in Tangshan City. However, owing to the problems of single processes and secondary pollution, advanced technologies should be adopted and selected to improve pollutant removal efficiency. Tangshan City mainly uses long-process steel production at present; in view of the current situation, this study selected six representative advanced desulfurization and denitrification technologies from the "Environmental Protection Technologies and Product Catalog Encouraged by Hebei Province" [53,54] and the "National Key Energy-saving Low-carbon Technology Promotion Catalog" [55]. Supplementary Sheet 4 lists the technology-related parameters. These six technologies can be divided into three categories to support whole cleaner process production: SC-Source Control, PC-Process Control, EC-End Control. According to the Accounting Standards for Business Enterprises, the annual depreciation rate of the equipment was set to $10 \%$. In addition, the government investment limit for technology introduction was set to CNY 500 million [56].

$$
\begin{gathered}
C L P^{\mathrm{P}}(t)=\sum_{t=1}^{t} \sum_{m=1}^{6} e p_{m}^{p} \times K_{m}(t), \\
K_{m}(t)=K_{m}(t-1)+\left(1-\theta_{m}\right) I_{m}(t)
\end{gathered}
$$

where $C L P^{\mathrm{P}}(t)$ denotes the air pollutants reduced by the whole-process control technology in year $t(\mathrm{en}), e p_{m}^{p}$ is the technical pollutant removal coefficient (ex), where in $\mathrm{m}$ values of 1 to 6 represent the six selected technologies. $K_{m}(t)$ denotes the capital stock of $\mathrm{m}$ technology in year $t$ (en) and is 0 when $\mathrm{t}$ is from 1 to $5 . I_{m}(t)$ is the investment of $\mathrm{m}$ technology in year $t(\mathrm{en})$, and $\theta_{m}$ is the depreciation rate of $\mathrm{m}$ technology (ex), set to $10 \%$ in this study.

Budgetary constraint. The cost of technology cannot exceed the total investment upper limit for air pollution control in Tangshan City in a certain year.

$$
\begin{gathered}
\sum I_{m}(t) \leq I_{G}(t), \\
I_{G}(t)=\gamma \sum I N V_{i}(t)
\end{gathered}
$$

where $\gamma$ is the ratio of total investment used for technology introduction (ex), and $I_{G}(t)$ is the total investment upper limit for air pollution control in year $t$ (ex).

\subsection{Assumptions and Scenarios}

According to the first level of China's Ambient Air Quality Standards, this study set the environmental target of reducing air pollutants to $50 \%$ by 2030 [57]. On this basis, we designed four scenarios to simulate the economic and environmental trends of Tangshan City under different paths (Table 1). The first scenario is the business as usual (BAU) scenario, which only optimizes the industrial structure from the mezzo level and conducts the dynamic simulation with the goal of maximizing the GDP. The other three scenarios were based on the BAU scenario and combine different cleaner production measures, including improving environmental efficiency by $10 \%$ (EFF), technology upgrades in the steel industry (TEC), and an integrated case (CLP). These simulations were performed to determine the optimal development path for Tangshan City by comparing the effects of each scenario. 
Table 1. Scenario setting.

\begin{tabular}{cccc}
\hline Scenario & $\begin{array}{c}\text { Industrial } \\
\text { Restructuring }\end{array}$ & $\begin{array}{c}\text { Environmental } \\
\text { Efficiency Increase }\end{array}$ & $\begin{array}{c}\text { Advanced } \\
\text { Technology }\end{array}$ \\
\hline Business as Usual Scenario (BAU) & $\sqrt{ }$ & $\times$ & $\times$ \\
Environmental Efficiency & & $\sqrt{ }$ & $\times$ \\
Improvement Scenario (EFF) & $\sqrt{ }$ & $\times$ & $\sqrt{ }$ \\
Technology Scenario (TEC) & $\sqrt{ }$ & $\sqrt{ }$ \\
Cleaner Production Scenario (CLP) & $\sqrt{ }$ & \\
\hline
\end{tabular}

\subsection{Sensitivity Analysis}

The rationality of the model was verified by comparing the BAU scenario prediction results in the model with actual data.

As summarized in Table 2, the simulation results were highly consistent with the actual data. Therefore, the model was deemed credible and the prediction results had practical significance. Cleaner production strategies were incorporated into the model starting in 2020 .

Table 2. Error rate between simulated result and real value.

\begin{tabular}{|c|c|c|c|c|}
\hline & Year & $\begin{array}{c}\text { Simulated } \\
\text { (Billion CNY) }\end{array}$ & $\begin{array}{c}\text { Observed } \\
\text { (Billion CNY) }\end{array}$ & Error (\%) \\
\hline \multirow{3}{*}{ GDP } & 2017 & 665.2 & 653.0 & 1.87 \\
\hline & 2018 & 695.3 & 695.5 & 0.02 \\
\hline & 2019 & 673.2 & 689.0 & 2.29 \\
\hline \multirow{2}{*}{ Output of steel industry } & 2017 & 519.22 & 526.97 & 1.22 \\
\hline & 2018 & 549.29 & 577.38 & 3.85 \\
\hline \multirow{3}{*}{ The value-added of tertiary industry } & 2017 & 236.38 & 228.3 & 3.54 \\
\hline & 2018 & 252.45 & 248.7 & 1.52 \\
\hline & 2019 & 269.62 & 274.55 & 1.8 \\
\hline \multirow{3}{*}{$\begin{array}{c}\text { Output value proportion of primary industry, } \\
\text { secondary industry, and } \\
\text { tertiary industry }\end{array}$} & 2017 & 0.09:0.55:0.36 & 0.08:0.53:0.39 & 1.86 \\
\hline & 2018 & 0.09:0.54:0.37 & 0.08:0.53:0.39 & 1.93 \\
\hline & 2019 & $0.09: 0.51: 0.40$ & $0.08: 0.52: 0.40$ & 1.5 \\
\hline
\end{tabular}

Note: The output value data of the steel industry in 2019 were not used as the inspection basis because of the change of statistical caliber. CNY: Chinese Yuan.

\section{Simulation Results Analysis}

Based on the comprehensive evaluation model of air pollution prevention and control policies in industrial cities, this study predicted and compared the social and economic development and atmospheric environmental impact in Tangshan City from 2020 to 2030 according to initial data of the region in 2016, as well as the optimization path and implementation scheme designed with the introduction of three incentive measures for cleaner production.

\subsection{Economic Development Recovery}

Figure 2 shows the economic development of Tangshan City under each scenario from 2020 to 2030 (Supplementary Sheet 5). The BAU scenario resulted in CNY 716 billion of the GDP in 2030, with an average annual growth rate of $1.1 \%$ over 10 years, which will make it difficult to achieve rapid economic growth. Under the EFF and TEC scenarios, the GDP will realize CNY 774.5 billion and CNY 1050.4 billion in 2030, with average annual growth rates of 1.5 and $4.3 \%$ from 2020 to 2030, respectively, verifying that both environment efficiency and technology improvements have a positive effect on economic development under the constraint of pollutants. The CLP scenario had the strongest increase in economic development. In this scenario, in 2030 the GDP will be CNY 1,263.4 billion, with an average annual growth rate of $6.56 \%$, thus reaching the national average. Therefore, the combination 
of efficiency improvements and technology introduction plays a more significant role in high quality development.

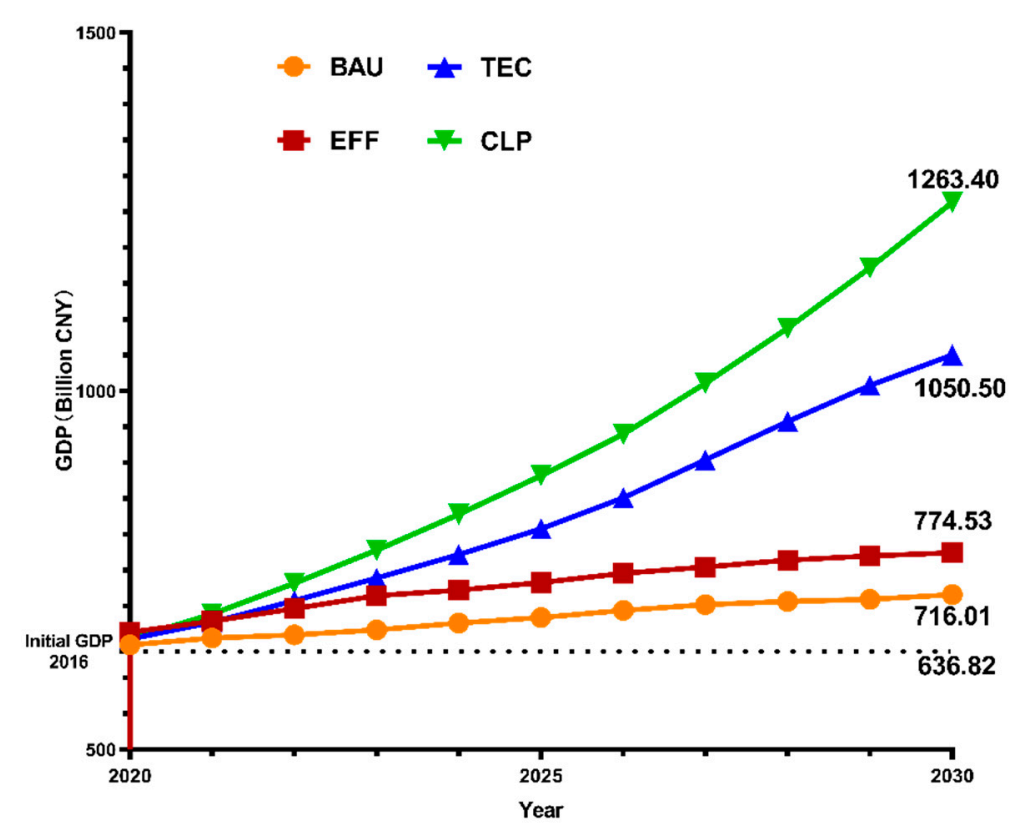

Figure 2. Gross regional production (GDP) of Tangshan City under four scenarios.

\subsection{Environmental Emissions Control}

The intensity of the pollutants decreased for all four scenarios (Supplementary Sheet 6). As shown in Figure 3, in 2030 the $\mathrm{NO}_{x}$ and $\mathrm{SO}_{2}$ intensities of the BAU scenario, which optimized only the industrial structure, fell by 68 and 56\%, respectively, compared with 2016 . After improving industry efficiency based on industrial optimization, the effect of emission reduction also improved. Meanwhile, under the EFF scenario, the emission intensities of $\mathrm{NO}_{\mathrm{x}}$ and $\mathrm{SO}_{2}$ decreased by 70 and $59 \%$, respectively, compared with 2016. Furthermore, when industrial structuring was combined with technology, the results showed further improvement. In particular, the TEC scenario was more effective in controlling $\mathrm{SO}_{2}$. Under this scenario, the intensities of $\mathrm{NO}_{\mathrm{x}}$ and $\mathrm{SO}_{2}$ were reduced by $70 \%$ compared to 2016 .

Finally, the cleaner production scenario, which considered all three measures, obtained the best results, wherein the $\mathrm{NO}_{\mathrm{x}}$ and $\mathrm{SO}_{2}$ emission intensities decreased by 87 and $97 \%$, respectively. The $\mathrm{NO}_{x}$ and $\mathrm{SO}_{2}$ emission reduction rates can reach 74 and $94 \%$, respectively. Compared with previous studies, the emissions of $\mathrm{SO}_{2}$ and $\mathrm{NO}_{\mathrm{x}}$ of the Beijing-Tianjin-Hebei (BTH) region were reduced by 40 and $44 \%$ in 2020, compared with those of 2012 [58-60]; $\mathrm{SO}_{2}$ and $\mathrm{NO}_{\mathrm{x}}$ in 2030 can be reduced by 85 and $74 \%$, respectively, compared to 2013 values after optimizing the industrial structure and improving the pollutant treatment efficiency in the $\mathrm{BTH}$ region [59]; and $\mathrm{SO}_{2}$ and $\mathrm{NO}_{\mathrm{x}}$ reduction can reach $60-79 \%$ as compared with the benchmark scenario by 2030 [60]. The forecast data are consistent with previous results and will improve further. In addition, the intensity of $\mathrm{NO}_{\mathrm{x}}$ will decrease less than $\mathrm{SO}_{2}$, indicating that $\mathrm{NO}_{\mathrm{x}}$ is more difficult to control and manage. Compared with other high steel production countries, Tangshan City will reach an emission intensity similar to the United States and Japan (demonstrated in Figure 3) in 2026 and 2028 [7], respectively, under the CLP scenario. 


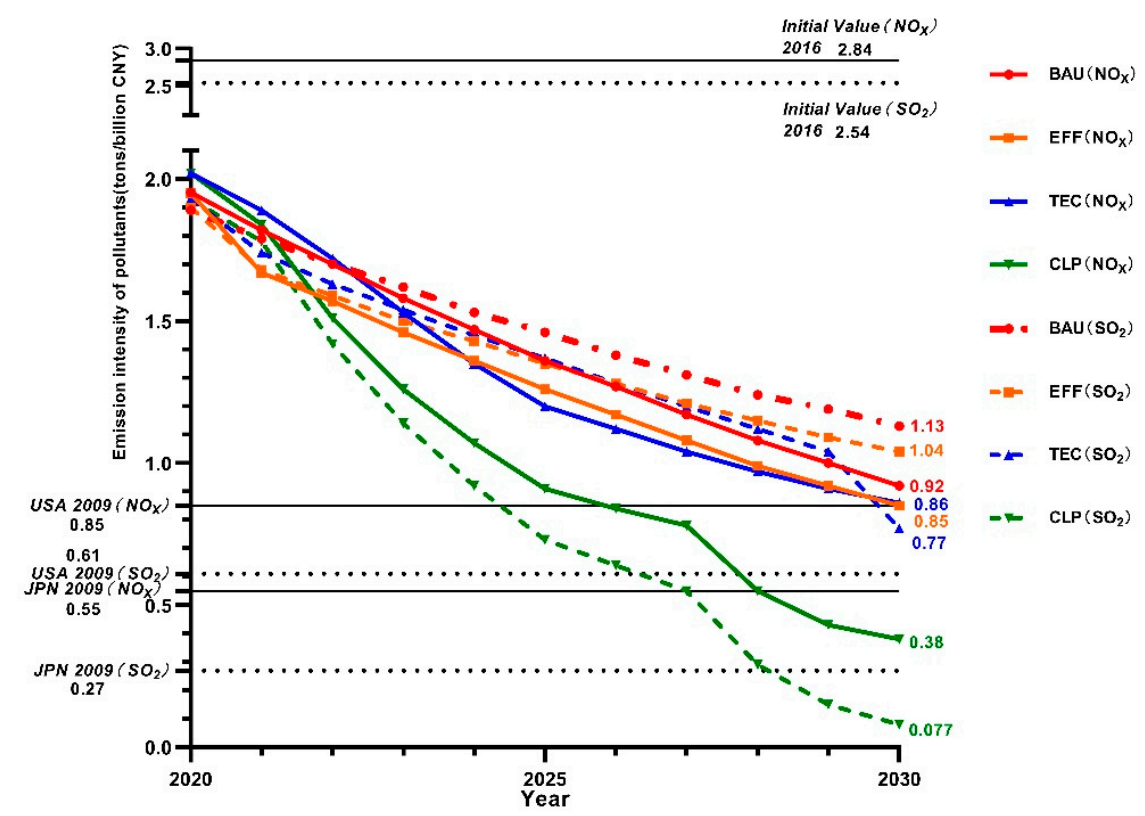

Figure 3. Emission intensity of $\mathrm{NO}_{\mathrm{x}}$ and $\mathrm{SO}_{2}$. USA $2009\left(\mathrm{NO}_{\mathrm{x}}\right)$ : $\mathrm{NO}_{\mathrm{x}}$ emissions intensity of the United States in 2009. USA $2009\left(\mathrm{SO}_{2}\right)$ : $\mathrm{SO}_{2}$ emissions intensity of the United States in 2009. JPN $2009\left(\mathrm{NO}_{\mathrm{x}}\right)$ : $\mathrm{NO}_{\mathrm{x}}$ emissions intensity of Japan in 2009. JPN $2009\left(\mathrm{SO}_{2}\right): \mathrm{SO}_{2}$ emissions intensity of Japan in 2009.

\subsection{Improving Heavy Industry Capacity without Environmental Deterioration}

As shown in Figure 4, the CLP scenario has a promoting effect on the development of most industries. In particular, the service industry increased the most, with its production in 2030 reaching $183.44 \%$ of its 2016 value. Thus, promoting the development of the service industry is essential for the balanced development of the environment and economy. Among the 11 industries, only mining industry production fell (13.13\%), indicating that the mining industry, as a typical resource-based industry, has insufficient potential in the future.

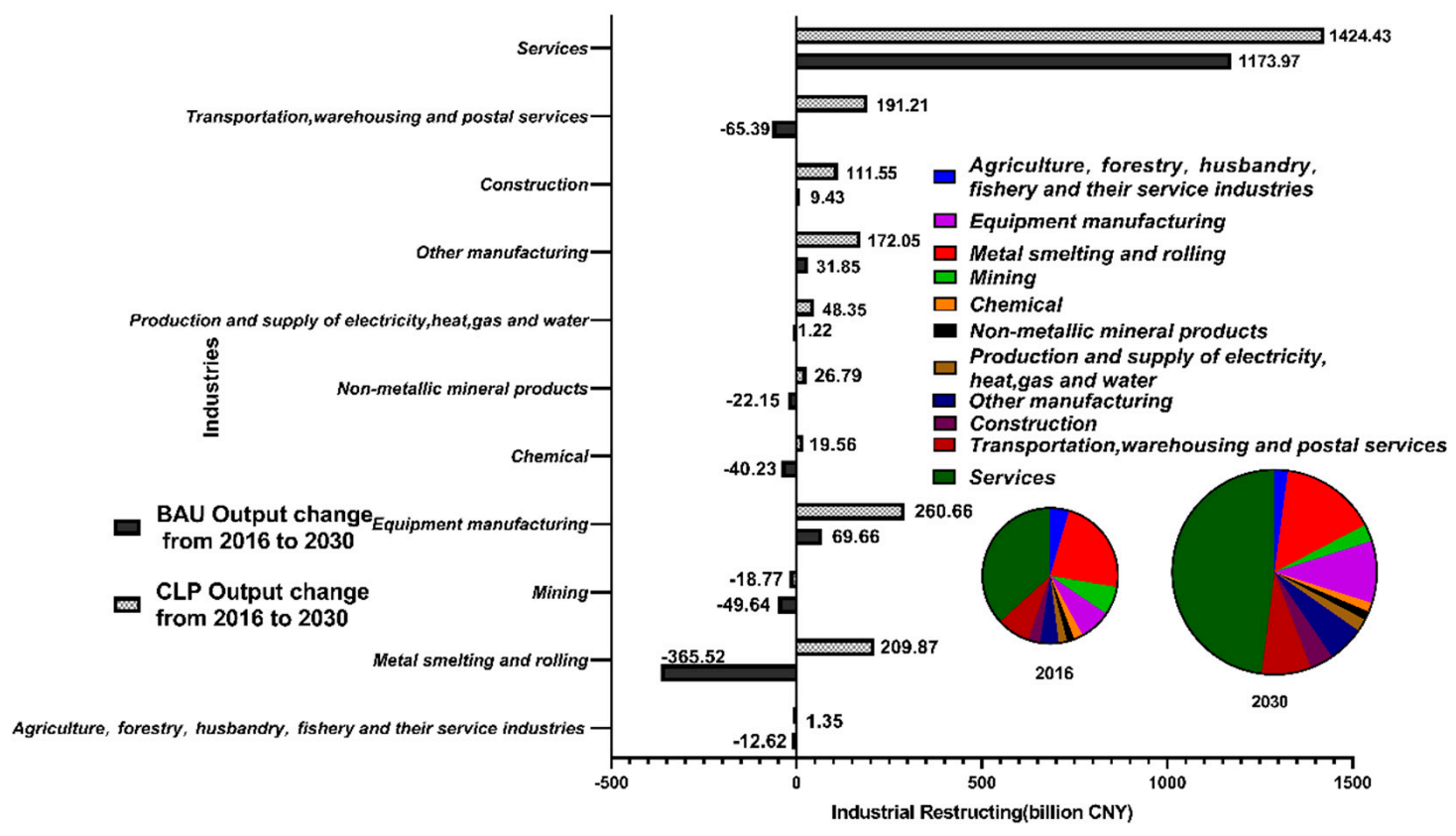

Figure 4. Industrial restructuring under cleaner production (CLP) scenario. 
As a pillar industry, the steel industry has a crucial impact on the economy of Tangshan City. Under the BAU scenario, the steel industry in Tangshan City experienced a severe decline. In 2030, it was approximately $25 \%$ of the base year value, and its production capacity was lowered by $75 \%$, which does not meet the proposed development requirements. However, the steel industry developed rapidly under the CLP scenario, and was $43 \%$ higher than the initial production and four times that of the BAU scenario. Further, since 2016, production decreased by 73 and 52\%, respectively, in the EFF and TEC scenarios, revealing that technology introduction has an inhibitory effect on the production capacity of the steel industry, and more significant effects can be achieved by improving the industry's environmental efficiency.

In addition, as the energy sources of Tangshan City, the electric heating, gas, and water supply industries assume critical tasks, such as power and water supply. However, this industry also produces severe pollution. As shown in Figure 5, there was no distinct change in this industry's production in the BAU scenario, but it reached 2.1 times the initial value in the CLP scenario, thus ensuring the normal progress of industrial activities and residential living in Tangshan City.
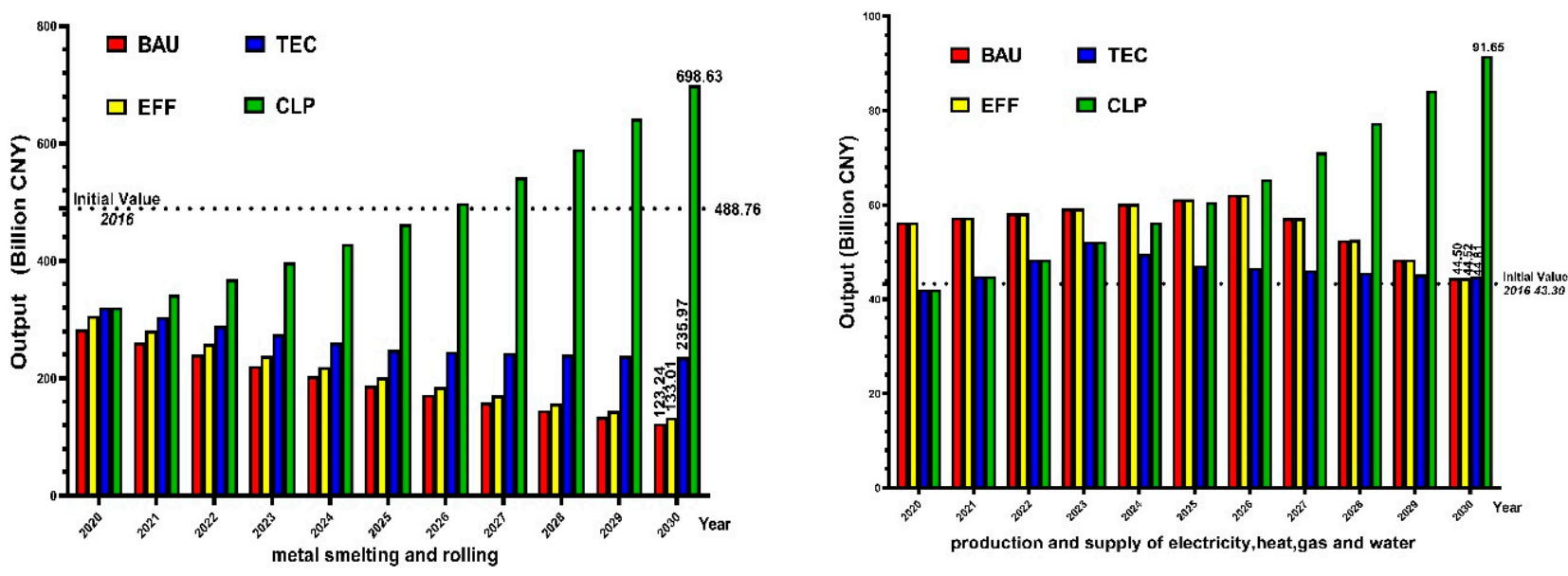

Figure 5. Development trends of major industries' production during simulation period 2020-2030.

Under the baseline scenario with industrial restructuring only, the emission intensities of $\mathrm{NO}_{\mathrm{x}}$ and $\mathrm{SO}_{2}$ decreased by 68 and $56 \%$, respectively, during the study period; however, the GDP was CNY 716 billion, and the average annual growth rate was only $1.1 \%$ in 2030 . In addition, because of the priority given by the simulation to developing industries with low atmospheric pollutant emissions, such as the service and equipment manufacturing industries, steel industry production decreased by $75 \%$, which is unreasonable for the steel-intensive city. Therefore, it was necessary to consider additional measures. When environmental efficiency improvements were added, the GDP rose by CNY 58 billion, and the emission intensities of $\mathrm{NO}_{x}$ and $\mathrm{SO}_{2}$ were 2 and $3 \%$ lower, respectively. When cleaner production technologies were added, the GDP rose by CNY 334 billion, the emission intensities of $\mathrm{NO}_{x}$ and $\mathrm{SO}_{2}$ were 2 and $14 \%$ lower, respectively, and the production of the steel industry increased by CNY 112.77 billion, compared with data of the BAU scenario in 2030. Thus, under the current budget conditions, continuous technological updates can effectively reduce pollution emissions. If the budget can be expanded, the cleaner production capacity may be further enlarged.

\subsection{Optimal Technologies Selection}

Figure 6 shows the investment in various technologies under the CLP scenario. A to $F$ represent the six technologies, respectively, and their specific parameters are shown in Supplementary Sheet 4 . In the initial period, investments are mainly focused on end treatment technology, then on source and process control technologies after 2027. Among 
the six demonstrative technologies adopted in this study, most funds are invested in GFX integrated flue gas purification systems and circuit waste heat recovery, indicating that these technologies are more efficient than others in the research area. Furthermore, in the CLP scenario simulation the reduction effect of $\mathrm{SO}_{2}$ was more obvious than that of $\mathrm{NO}_{\mathrm{x}}$. One reason is that the GFX integrated flue gas purification system has a significant $\mathrm{SO}_{2}$ removal effect. Among the two integrated desulfurization and denitrification technologies, the simulation always selected the integrated activated coke desulfurization and denitrification technology, indicating that this technology has better removal efficiency.
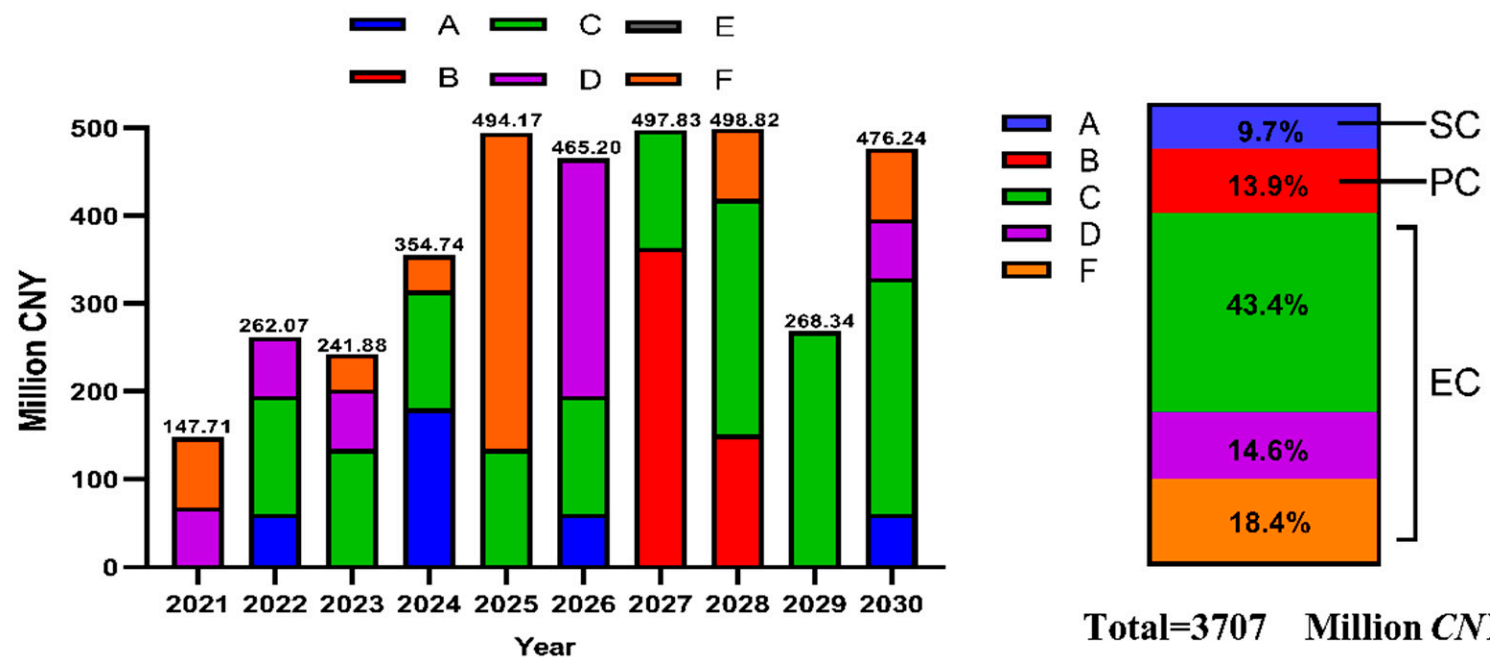

Total $=3707 \quad$ Million $C N Y$

Figure 6. Optimal technology selections in the CLP scenario. SC: Source Control, PC: Process Control, EC: End Control.

The technology selection of the most effective pathway for pollution control in the steel city was determined to be the CLP scenario. We found that the end treatment technologies were more efficient at the former stage, while the source and process were chosen at the latter stage. This study demonstrated only the mechanism of technology selection in industrial cities; considering that there may be hundreds of technologies, they can be further extended to the DOMCLP model in practice.

\subsection{Intensified Decoupling Effect}

Through a decoupling analysis of the simulated prediction data, this research further investigated the trade-off relationship patterns between the economy and environment after introducing the cleaner production approach. The Organization for Economic Cooperation and Development defined decoupling as simultaneous economic growth and industrial pollution emissions change and divided the ratio of pollutant emissions to the GDP in the final period by the base period to determine the decoupling index [61]. With further development of the decoupling theory, some scholars have found that the decoupling index will vary with the choice of base period, making it difficult to accurately judge the decoupling state of economic growth and environment. To remove the error in the base period selection, Tapio [62,63] improved a decoupling elastic coefficient. In this study, the function is:

$$
\varepsilon=\frac{\left[T P^{p}(t+1)-T P^{p}(t)\right] / T P^{p}(t)}{[G D P(t+1)-G D P(t)] / G D P(t)}=\frac{\Delta T P^{p} / T P^{p}(t)}{\Delta G D P / G D P(t)}
$$

where $\varepsilon$ is the coefficient of decoupling elasticity, and $\triangle T P$ and $\triangle G D P$ are air pollution emissions and GDP changes in two adjacent periods, respectively. When the elasticity is less than 0 , the economy and environment are in a state of strong decoupling, achieving both economic growth and environmental improvement. The greater the absolute value, the more coordination there is between the environment and the economy. When the elasticity 
is between 0 and 1 , the economy and environment are weakly decoupled. This means that although the economy is growing, environmental pressure has also increased [64]. By classifying the 2016-2030 simulation results of Tangshan City, we obtained the decoupling relationship (as shown in Figure 7).

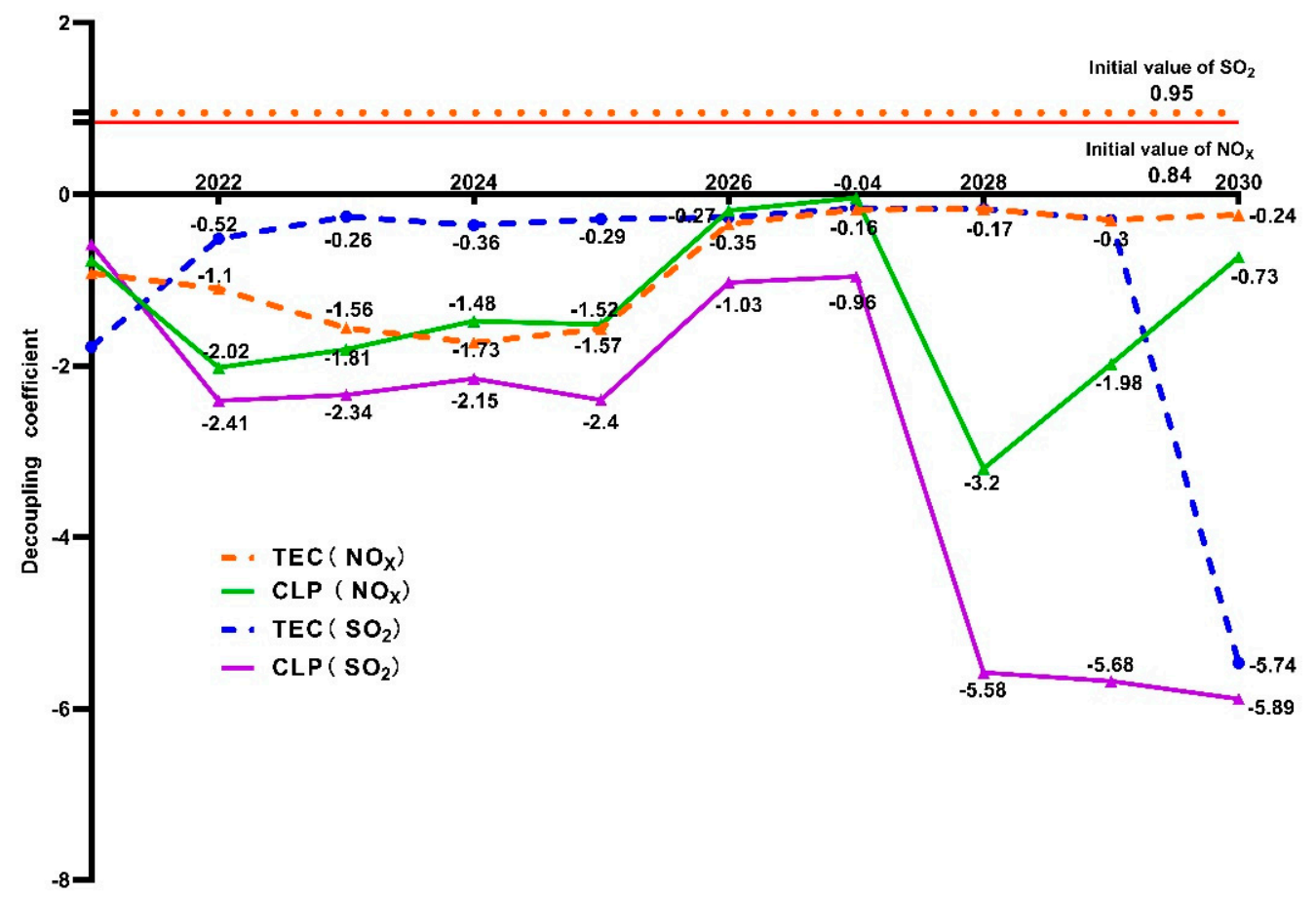

Figure 7. Decoupling predictions for Tangshan City from 2021 to 2030.

At the beginning of the period, both air pollutants were weakly decoupled with economic development, which means that economic development and pollutant emission reductions cannot be achieved together. However, a strong decoupling of economic development and the environment can be achieved after introducing advanced technology and implementing cleaner production. Compared with the TEC scenario, the CLP scenario had a greater impact on decoupling, and this effect will increase after 2027. At the end of the prediction period, this decoupling effect will be greatly enhanced, thereby ameliorating the weak decoupling relationship in the base period. In particular, when technology introduction was combined with environmental efficiency improvement, a stronger decoupling relationship was achieved. Moreover, the decoupling of economic development and $\mathrm{SO}_{2}$ is stronger than that of $\mathrm{NO}_{x}$, revealing that $\mathrm{SO}_{2}$ is easier to control and thereby to enhance decoupling with the economy.

\section{Discussion}

Based on the demand for environmental improvement and the urgent need for transformation in industrial cities with heavy air pollution, this study explored the optimal cleaner production pathway using integrated stimulus policies from comprehensive perspectives by overcoming problems in the existing research, which were mainly analyzed from a single perspective $[12,24,26]$. Herein, macro-industrial restructuring, mezzoindustry environmental efficiency improvement, and micro-technology optimal selection, the "Top-Down" and "Bottom-Up" schemes were combined to examine the best roadmap for promoting transformation and development in a typical industrial city to determine if cleaner production can solve the problems of economic downward pressure and serious environmental air pollution. This study improved the methodology with integration of system dynamics and Input-Output modeling focused on optimal selection of pollution treatment technologies [29] to further concretize technical factors into cleaner production 
schemes. Moreover, a decoupling analysis of the economy and environment was performed using dynamic simulation prediction results to overcome the limitation where the decoupling coefficient is primarily used to analyze historical and current data $[32,33]$. This cleaner production decision optimization model (DOMCLP) can become a necessary measure to promote the high quality development of regions dominated by industry and cities with pollution problems.

Through model simulation of a typical air-polluted city, Tangshan City, from 2016 to 2030, we found the following. Firstly, the proposed comprehensive cleaner production incentive approaches were proved to be efficient to promote the balanced development of the economy and environment. Under the cleaner production scenario, which combines all three measures, the GDP of Tangshan City can reach an average annual growth rate of $6.56 \%$, which meets the requirement of China's growth plan, reversing the current slow economic development trend. Furthermore, steel and electric heating industry production can achieve capacity growth over the study period without deteriorating air environment, in which the intensity of $\mathrm{SO}_{2}$ and $\mathrm{NO}_{\mathrm{x}}$ can be reduced by 97 and $87 \%$, and the total reduction rates can reach 94 and $74 \%$, respectively. Under the optimal scenario, which effectively combined three intensive strategies, air pollutant emission control has a further better effect than those found in previous studies in the Beijing-Tianjin-Hebei region (BTH) and China [29,58-60]. In addition, the optimal air pollutant control technology upgrading was proved to be more effective than the other two incentive measures in achieving balanced economic and environmental development in industrial cities. In the optimal scenario, an input of 3707 million to technology can achieve a marginal CNY 213 billion GDP growth. Furthermore, the treatment of pollutants should not only consider the end result but also include the production process. Only by combining the whole process of cleaner production technology can the maximum effect be achieved [65]. Upgrading technology can also realize a strong decoupling effect between economic development and environmental improvement.

\section{Conclusions}

This study explored the optimal cleaner production pathway using a comprehensive stimulus policy evaluation and dynamic simulation approach, from "Bottom-Up" to "TopDown", by overcoming problems in the existing research that were analyzed mainly from a single perspective. The DOMCLP simulated the environmental and economic impacts of different cleaner production strategy mixes from 2020 to 2030. Simulation results proved that: Heavily air-polluted cities can achieve economic growth without deteriorating air environment; the decoupling degree intensifies steadily, which can support a high quality development target. Meanwhile, even though the industry structure is optimized gradually, heavy industries can maintain a steady development and occupy leading positions. Furthermore, the optimal air pollutant control technology upgrading is proved to be more effective than other incentive measures, and technology choice shifts from end treatment to source and process treatment in the long run.

Therefore, it can be inferred that policy measures, including increasing the number of fiscal subsidies, and an optimal technologies selection plan in both location and time scales can effectively improve the scenario results. Further, the decoupling effect of $\mathrm{SO}_{2}$ is more obvious than that of $\mathrm{NO}_{\mathrm{x}}$, indicating that it is easier to achieve the decoupling of $\mathrm{SO}_{2}$ emission reduction and economic development and suggesting it is easier to remove. Further technology and financial investment in $\mathrm{NO}_{x}$ reduction can benefit trade-off improvement. For local authorities, heavy industries should not be simply cut down to improve air quality when they format an industry development plan.

Asian countries and emerging economies are the main producers and consumers of industry products, and they are all confronted with the same difficulties of environment protection and economic development; this study can benefit heavy pollution industries' cleaner production for these regions in practice. This study presented insights that will be useful for both regional planners and future studies. However, challenges still exist; this 
study only considered atmospheric environment in industrial cities, while water pollution was not considered. Also, Tangshan City was selected as a typical research area to conduct an empirical study; the general patterns of transformation and development in China's industrial cities can be further analyzed. Further research will be conducted to address these limitations in future.

All abbreviations used in the text: DOMCLP-dynamic optimization model of cleaner production, 3E; Energy-Economy-Environment, HAP: Household Air Pollution, IAP: Industrial Air Pollution, ED: Energy Demand, ES: Energy Supply, TP: Total Pollution, GDP: Gross Domestic Product, PLO1: Cleaner Production Strategy 1, POL2: Cleaner Production Strategy 2, PLO3: Cleaner Production Strategy 3, en: endogenous, ex: exogenous, SNCR: Selective Non-Catalytic Reduction denitrification technology, CNY: China Yuan, BAU: Business as Usual Scenario, EFF: Environmental Efficiency Improvement Scenario, TEC: Technology Scenario, CLP: Cleaner Production Scenario, USA 2009 ( $\mathrm{NO}_{\mathrm{x}}$ ): $\mathrm{NO}_{\mathrm{x}}$ emissions intensity of the United States in 2009, USA $2009\left(\mathrm{SO}_{2}\right): \mathrm{SO}_{2}$ emissions intensity of the United States in 2009, JPN 2009 ( $\left.\mathrm{NO}_{\mathrm{x}}\right)$ : $\mathrm{NO}_{\mathrm{x}}$ emissions intensity of Japan in 2009. JPN 2009 $\left(\mathrm{SO}_{2}\right): \mathrm{SO}_{2}$ emissions intensity of Japan in 2009, BTH: Beijing-Tianjin-Hebei region.

Supplementary Materials: The following are available online at https://www.mdpi.com/article/10.3 390/su13168951/s1, Supplementary Sheet 1: Input-Output table, Supplementary Sheet 2: Emissions, Supplementary Sheet 3: Emission coefficient of each industry sector and residents, Supplementary Sheet 4: Technical Parameter, Supplementary Sheet 5: Simulation results of GDP in Tangshan city, Supplementary Sheet 6: Simulation results of emissions in Tangshan city.

Author Contributions: Conceptualization, N.X. and J.S.; methodology, J.S., X.L. and N.X.; software, J.S., N.X.; validation, Y.Z. and G.L.; formal analysis, N.X., J.S., X.L. and G.L.; investigation, J.S. and Y.Z.; resources, N.X. and J.S.; data curation, J.S., Y.Z. and X.L.; writing-original draft preparation, N.X., J.S. and Y.Z.; writing-review and editing, N.X., J.S. and G.L.; visualization, J.S. and Y.Z.; supervision, N.X.; project administration, N.X.; funding acquisition, N.X. All authors have read and agreed to the published version of the manuscript.

Funding: This research was funded by the Natural Science Foundation of Beijing Municipality [Grant Number. 9214021], the National Natural Science Foundation of China [Grant Number. 41701635].

Institutional Review Board Statement: Not applicable.

Informed Consent Statement: Not applicable.

Data Availability Statement: Data is contained within the article or Supplementary Material.

Acknowledgments: We would like to especially thank the reviewers for their helpful comments.

Conflicts of Interest: The authors declare no conflict of interest.

\section{References}

1. Ryan, N.; Miller, S.; Skerlos, S.; Cooper, D. Reducing $\mathrm{CO}_{2}$ emissions from U.S. steel consumption by $70 \%$ by 2050 . Environ. Sci. Technol. 2020, 54, 14598-14608. [CrossRef]

2. National Bureau of Statistics. China Statistical Yearbook 2020; China Statistics Press: Beijing, China, 2020.

3. Wu, P.; Low, S.P.; Xia, B.; Zuo, J. Achieving transparency in carbon labelling for construction materials-Lessons from current assessment standards and carbon labels. Environ. Sci. Policy 2014, 44, 11-25. [CrossRef]

4. Statistical Bulletin of the National Economic and Social Development of Tangshan City. 2019. Available online: http://www. tsxxg.com/thread-457204-1-1.html (accessed on 2 April 2020).

5. World Steel Association Homepage. Available online: https://www.worldsteel.org/zh/ (accessed on 16 August 2019).

6. The Ministry of Ecology and Environment Reported the State of Surface Water and Air Quality in China in September and JanuarySeptember. Available online: https:/ /www.mee.gov.cn/xxgk2018/xxgk/xxgk15/202010/t20201020_803893.html (accessed on 20 October 2020).

7. World Input-Output Database Homepage. Available online: http:/ /www.wiod.org/database/eas13 (accessed on 16 August 2019).

8. Notice on Supporting the Construction of The First Batch of Industrial Transformation and Upgrading Demonstration Zones in Old Industrial Cities and Resource-Based Cities. Available online: http://www.gov.cn/xinwen/201704/21/5188011/files/8ebf2 8a6bfcd49d783dd66c2952ea688.pdf (accessed on 21 April 2017).

9. Shi, L.; Liu, J.; Wang, Y.; Chiu, A. Cleaner production progress in developing and transition countries. J. Clean. Prod. 2021, 278, 123763. [CrossRef] 
10. Sustainable Consumption \& Production Branch: Resource Efficient and Cleaner Production. Available online: http:/ / www.unep. $\mathrm{fr} / \mathrm{scp} / \mathrm{cp} /$ (accessed on 2 September 2016).

11. Loiseau, E.; Saikku, L.; Antikainen, R.; Droste, N.; Hansjürgens, B.; Pitkänen, K.; Leskinen, P.; Kuikman, P.; Thomsen, M. Green economy and related concepts: An overview. J. Clean. Prod. 2016, 139, 361-371. [CrossRef]

12. Wu, R.; Dai, H.; Geng, Y.; Xie, Y.; Masui, T.; Liu, Z.; Qian, Y. Economic Impacts from PM2.5 Pollution-Related Health Effects: A Case Study in Shanghai. Environ. Sci. Technol. 2017, 51, 5035-5042. [CrossRef] [PubMed]

13. Almer, C.; Winkler, R. Analyzing the effectiveness of international environmental policies: The case of the Kyoto Protocol. J. Environ. Econ. Manag. 2017, 82, 125-151. [CrossRef]

14. Zhang, H.; Wang, S.; Hao, J.; Wang, X.; Wang, S.; Chai, F.; Li, M. Air pollution and control action in Beijing. J. Clean. Prod. 2016, 112, 1519-1527. [CrossRef]

15. Von Der Assen, N.; Müller, L.J.; Steingrube, A.; Voll, P.; Bardow, A. Selecting $\mathrm{CO}_{2}$ Sources for $\mathrm{CO}_{2}$ Utilization by EnvironmentalMerit-Order Curves. Environ. Sci. Technol. 2016, 50, 1093-1101. [CrossRef]

16. Yong, J.Y.; Klemeš, J.J.; Varbanov, P.S.; Huisingh, D. Cleaner energy for cleaner production: Modelling, simulation, optimisation and waste management. J. Clean. Prod. 2016, 111, 1-16. [CrossRef]

17. Zheng, S.; Yi, H.; Li, H. The impacts of provincial energy and environmental policies on air pollution control in China. Renew. Sustain. Energy Rev. 2015, 49, 386-394. [CrossRef]

18. Song, L.; Wang, P.; Xiang, K.; Chen, W.Q. Regional disparities in decoupling economic growth and steel stocks: Forty years of provincial evidence in China. J. Environ. Manag. 2020, 271, 111035. [CrossRef]

19. Qi, C.; Wang, Q.; Ma, X.; Ye, L.; Yang, D.; Hong, J. Inventory, environmental impact, and economic burden of GHG emission at the city level: Case study of Jinan, China. J. Clean. Prod. 2018, 192, 236-243. [CrossRef]

20. Lu, Y.; Wang, Y.; Zhang, W.; Hubacek, K.; Bi, F.; Zuo, J.; Jiang, H.; Zhang, Z.; Feng, K.; Liu, Y.; et al. Provincial air pollution responsibility and environmental tax of China based on interregional linkage indicators. J. Clean. Prod. 2019, 235, 337-347. [CrossRef]

21. Hu, X.; Liu, J.; Yang, H.; Meng, J.; Wang, X.; Ma, J.; Tao, S. Impacts of Potential China's Environmental Protection Tax Reforms on Provincial Air Pollution Emissions and Economy. Earth's Futur. 2020, 8, 1-11. [CrossRef]

22. Zhang, W.; Wang, F.; Hubacek, K.; Liu, Y.; Wang, J.; Feng, K.; Jiang, L.; Jiang, H.; Zhang, B.; Bi, J. Unequal Exchange of Air Pollution and Economic Benefits Embodied in China's Exports. Environ. Sci. Technol. 2018, 52, 3888-3898. [CrossRef] [PubMed]

23. Wang, H.; Zhang, Y.; Zhao, H.; Lu, X.; Zhang, Y.; Zhu, W.; Nielsen, C.P.; Li, X.; Zhang, Q.; Bi, J.; et al. Trade-driven relocation of air pollution and health impacts in China. Nat. Commun. 2017, 8, 738. [CrossRef] [PubMed]

24. Song, J.; Wang, B.; Fang, K.; Yang, W. Unraveling economic and environmental implications of cutting overcapacity of industries: A city-level empirical simulation with input-output approach. J. Clean. Prod. 2019, 222, 722-732. [CrossRef]

25. Sun, X.; Li, W.; Xie, Y.; Huang, G.; Dong, C.; Yin, J. An optimization model for regional air pollutants mitigation based on the economic structure adjustment and multiple measures: A case study in Urumqi city, China. J. Environ. Manag. 2016, 182, 59-69. [CrossRef] [PubMed]

26. Wang, Y.; Li, M.; Wang, L.; Wang, H.; Zeng, M.; Zeng, B.; Qiu, F.; Sun, C. Can remotely delivered electricity really alleviate smog? An assessment of China's use of ultra-high voltage transmission for air pollution prevention and control. J. Clean. Prod. 2020, 242, 118430. [CrossRef]

27. Wu, D.; Ma, X.; Zhang, S. Integrating synergistic effects of air pollution control technologies: More cost-effective approach in the coal-fired sector in China. J. Clean. Prod. 2018, 199, 1035-1042. [CrossRef]

28. Gao, C.K.; Na, H.M.; Song, K.; Tian, F.; Strawa, N.; Du, T. Technologies-based potential analysis on saving energy and water of China's iron and steel industry. Sci. Total Environ. 2020, 699, 134225. [CrossRef] [PubMed]

29. Xu, F.; Cui, F.; Xiang, N. Roadmap of green transformation for a steel-manufacturing intensive city in China driven by air pollution control. J. Clean. Prod. 2021, 283, 124643. [CrossRef]

30. Gautam, S.; Patra, A.K.; Kumar, P. Status and chemical characteristics of ambient PM2.5 pollutions in China: A review. Environ. Dev. Sustain. 2019, 21, 1649-1674. [CrossRef]

31. Gautam, S.; Yadav, A.; Tsai, C.J.; Kumar, P. A review on recent progress in observations, sources, classification and regulations of PM2.5 in Asian environments. Environ. Sci. Pollut. Res. 2016, 23, 21165-21175. [CrossRef]

32. Bai, C.; Chen, Y.; Yi, X.; Feng, C. Decoupling and decomposition analysis of transportation carbon emissions at the provincial level in China: Perspective from the 11th and 12th Five-Year Plan periods. Environ. Sci. Pollut. Res. 2019, 26, 15039-15056. [CrossRef] [PubMed]

33. Xia, H.; Ding, L.; Yang, S.; Wu, A. Socioeconomic factors of industrial air pollutants in Zhejiang Province, China: Decoupling and Decomposition analysis. Environ. Sci. Pollut. Res. 2020, 27, 28247-28266. [CrossRef]

34. Wang, X.; Gao, X.; Shao, Q.; Wei, Y. Factor decomposition and decoupling analysis of air pollutant emissions in China's iron and steel industry. Environ. Sci. Pollut. Res. 2020, 27, 15267-15277. [CrossRef]

35. Ouyang, X.; Shao, Q.; Zhu, X.; He, Q.; Xiang, C.; Wei, G. Environmental regulation, economic growth and air pollution: Panel threshold analysis for OECD countries. Sci. Total Environ. 2019, 657, 234-241. [CrossRef] [PubMed]

36. Li, N.; Zhang, X.; Shi, M.; Hewings, G.J.D. Does China's air pollution abatement policy matter? An assessment of the BeijingTianjin-Hebei region based on a multi-regional CGE model. Energy Policy 2019, 127, 213-227. [CrossRef] 
37. Wang, Y.; Li, X.; Sun, Y.; Zhang, L.; Qiao, Z.; Zhang, Z.; Zheng, H.; Meng, J.; Lu, Y.; Li, Y. Linkage analysis of economic consumption, pollutant emissions and concentrations based on a city-level multi-regional input-output (MRIO) model and atmospheric transport. J. Environ. Manag. 2020, 270, 110819. [CrossRef]

38. Cansino, J.M.; Román, R.; Rueda-Cantuche, J.M. Will China comply with its 2020 carbon intensity commitment? Environ. Sci. Policy 2015, 47, 108-117. [CrossRef]

39. Cai, Y.; Applegate, S.; Yue, W.; Cai, J.; Wang, X.; Liu, G.; Li, C. A hybrid life cycle and multi-criteria decision analysis approach for identifying sustainable development strategies of Beijing's taxi fleet. Energy Policy 2017, 100, 314-325. [CrossRef]

40. Gilardino, A.; Rojas, J.; Mattos, H.; Larrea-Gallegos, G.; Vázquez-Rowe, I. Combining operational research and Life Cycle Assessment to optimize municipal solid waste collection in a district in Lima (Peru). J. Clean. Prod. 2017, 156, 589-603. [CrossRef]

41. Technology and Innovation Report 2018: Harnessing Frontier Technologies for Sustainable Development; United Nations Publication: Geneva, Switzerland, 2018.

42. Guo, R.; Lv, S.; Liao, T.; Xi, F.; Zhang, J.; Zuo, X.; Cao, X.; Feng, Z.; Zhang, Y. Classifying green technologies for sustainable innovation and investment. Resour. Conserv. Recycl. 2020, 153, 104580. [CrossRef]

43. Bryan, T. China's air pollution crisis: Science and policy perspectives. Environ. Sci. Policy 2019, 92, $275-280$.

44. Xu, F.; Xiang, N.; Tian, J.; Chen, L. 3Es-based optimization simulation approach to support the development of an eco-industrial park with planning towards sustainability: A case study in Wuhu, China. J. Clean. Prod. 2017, 164, 476-484. [CrossRef]

45. Ma, Y.; Yan, J.; Sha, J.; He, G.; Song, C.; Fan, S.; Ke, W. Dynamic simulation of the atmospheric environment improved by a focus on clean energy utilization of resource-based cities in China. J. Clean. Prod. 2018, 192, 396-410. [CrossRef]

46. Chuah, L.F.; Klemeš, J.J.; Yusup, S.; Bokhari, A.; Akbar, M.M. A review of cleaner intensification technologies in biodiesel production. J. Clean. Prod. 2017, 146, 181-193. [CrossRef]

47. Wang, X.; Zhang, Q.; Xu, L.; Tong, Y.; Jia, X.; Tian, H. Water-energy-carbon nexus assessment of China's iron and steel industry: Case study from plant level. J. Clean. Prod. 2020, 253, 119910. [CrossRef]

48. Geng, Z.; Chen, Q.; Xia, Q.; Kirschen, D.S.; Kang, C. Environmental Generation Scheduling Considering Air Pollution Control Technologies and Weather Effects. IEEE Trans. Power Syst. 2017, 32, 127-136. [CrossRef]

49. Tangshan Statistical Yearbook 2017; China Statistics Press: Beijing, China, 2018. (In Chinese)

50. Accounting Standards for Enterprises-Basic Standards. Available online: http://kjs.mof.gov.cn/zt/kjzzss/kuaijizhunzeshishi/20 0806/t20080618_46213.html (accessed on 18 June 2008).

51. Mei, X.; Bai, J.; Chen, S.; Zhou, M.; Jiang, P.; Zhou, C.; Fang, F.; Zhang, Y.; Li, J.; Long, M.; et al. Efficient $\mathrm{SO}_{2}$ Removal and Highly Synergistic $\mathrm{H}_{2} \mathrm{O}_{2}$ Production Based on a Novel Dual-Function Photoelectrocatalytic System. Environ. Sci. Technol. 2020, 54, 11515-11525. [CrossRef]

52. Liu, W.; Wu, B.; Bai, X.; Liu, S.; Liu, X.; Hao, Y.; Liang, W.; Lin, S.; Liu, H.; Luo, L.; et al. Migration and Emission Characteristics of Ammonia/Ammonium through Flue Gas Cleaning Devices in Coal-Fired Power Plants of China. Environ. Sci. Technol. 2019. [CrossRef]

53. Hebei Environmental Protection Industry Association on the Release of "Hebei Province to Encourage Environmental Protection Technology, Product Catalogue (the First Batch) Letter. Available online: http:/ /www.hb12369.net/201501/t20150123_45461. $\mathrm{htmlhd} / \mathrm{kjbz} / \mathrm{kjdt} /$ (accessed on 23 January 2015).

54. Hebei Environmental Protection Industry Association on the Release of Hebei Province to Encourage Environmental Protection Technology, Product Catalogue (the Second Batch) Letter. Available online: http:/ /www.hb12369.net/201601/t20160120_49376. html (accessed on 20 January 2016).

55. Publicity on the Energy Saving Technologies and Updated Energy Saving Technologies to be Included in the National Key Energy Saving and Low-Carbon Technology Promotion Catalogue. Available online: https://www.ndrc.gov.cn/fggz/hjyzy/jnhnx/2015 12/W020190910595799295318.pdf (accessed on 10 September 2019).

56. China Statistical Yearbook on Environment 2017; China Statistics Press: Beijing, China, 2018. (In Chinese)

57. Ambient Air Quality Stand Ards. Available online: http://www.mee.gov.cn/ywgz/fgbz/bz/bzwb/dqhjbh/dqhjzlbz/201203 /W020120410330232398521.pdf (accessed on 10 April 2012).

58. Tong, D.; Geng, G.; Jiang, K.; Cheng, J.; Zheng, Y.; Hong, C.; Yan, L.; Zhang, Y.; Chen, X.; Bo, Y.; et al. Energy and emission pathways towards PM2.5 air quality attainment in the Beijing-Tianjin-Hebei region by 2030. Sci. Total Environ. 2019, 692, 361-370. [CrossRef]

59. Cai, S.; Wang, Y.; Zhao, B.; Wang, S.; Chang, X.; Hao, J. The impact of the "Air Pollution Prevention and Control Action Plan" on PM2.5 concentrations in Jing-Jin-Ji region during 2012-2020. Sci. Total Environ. 2017, 580, 197-209. [CrossRef]

60. Guo, X.; Zhao, L.; Chen, D.; Jia, Y.; Chen, D.; Zhou, Y.; Cheng, S. Prediction of reduction potential of pollutant emissions under the coal cap policy in BTH region, China. J. Environ. Manag. 2018, 225, 25-31. [CrossRef] [PubMed]

61. Indicators to Measure Decoupling of Environment Pressure from Economic Growth. Available online: http://www.oecd.org/ environment/indicators-modelling-outlooks/1933638.pdf (accessed on 20 November 2019).

62. Tapio, P. Towards a theory of decoupling: Degrees of decoupling in the EU and the case of road traffic in Finland between 1970 and 2001. Transp. Policy 2005, 12, 137-151. [CrossRef]

63. Tapio, P.; Banister, D.; Luukkanen, J.; Vehmas, J.; Willamo, R. Energy and transport in comparison: Immaterialisation, dematerialisation and decarbonisation in the EU15 between 1970 and 2000. Energy Policy 2007, 35, 433-451. [CrossRef] 
64. Xia, Y.; Zhong, M. Relationship between decoupling theory of Economic Development and Environmental pollution and EKC Hypothesis-Also on Decoupling Division of Chinese prefecture-Level Cities. China Popul. Resour. Environ. 2016, 26, 8-16. (In Chinese)

65. Yang, X.; Teng, F. The air quality co-benefit of coal control strategy in China. Resour. Conserv. Recycl. 2018, 129, 373-382. [CrossRef] 